\title{
Expression of Connexin 43 in Synovial Tissue of Patients With Rheumatoid Arthritis
}

\author{
Tomohiro MATSUKI, ${ }^{1}$ Yuji ARAI, ${ }^{1}$ Shinji TSUCHIDA, ${ }^{1}$ Ryu TERAUCHI, ${ }^{1}$ Ryo ODA, ${ }^{1}$ \\ Hiroyoshi FUJIWARA, ${ }^{1}$ Osam MAZDA, ${ }^{2}$ Toshikazu KUBO ${ }^{1}$ \\ ${ }^{1}$ Department of Orthopedics, Graduate School of Medical Science, Kyoto Prefectural University of Medicine, Kyoto, Japan \\ ${ }^{2}$ Department of Immunology, Graduate School of Medical Science, Kyoto Prefectural University of Medicine, Kyoto, Japan
}

\begin{abstract}
Objectives: This study aims to identify the distribution and expression level of connexin 43 (Cx43) in synovial tissue in patients with rheumatoid arthritis (RA).

Patients and methods: The expression of Cx43 in synovial tissue from eight patients with RA ( 2 males, 6 females; mean age $59.5 \pm 2.7$ years; range 52 to 71 years), five patients with osteoarthritis ( 2 males, 3 females; mean age $68.4 \pm 2.7$ years; range 61 to 81 years), and one normal female subject (mean age 61 year) was analyzed by quantitative reverse transcriptase polymerase chain reaction and immunohistochemistry of tissue sections. Induction of Cx43 following stimulation of human RA synovial fibroblasts with tumor necrosis factor-alpha (TNF- $\alpha$ ) cultures was examined by quantitative reverse transcriptase polymerase chain reaction. The effect of small interfering ribonucleic acid targeting Cx43 (siCx43) on the expression of TNF- $\alpha$ and interleukin- 6 was examined using quantitative reverse transcriptase polymerase chain reaction and enzyme-linked immunosorbent assays.

Results: Connexin 43 was highly expressed in RA synovial tissue, which also expressed TNF- $\alpha$, but was expressed lower in osteoarthritis and normal synovial tissue. Expression of Cx43 was markedly up-regulated in RA synovial fibroblasts after stimulation with TNF- $\alpha$. The over-expression of pro-inflammatory cytokines was suppressed by transfection of siCx43.

Conclusion: This study shows that Cx43 is expressed in RA synovial tissue and that its expression is induced by stimulation with TNF- $\alpha$. The expression of the pro-inflammatory cytokines was inhibited by transfection of siCx43. Cx43 may be a novel marker of inflammation in RA synovial tissue.

Keywords: Connexin 43; gap junction; pro-inflammatory cytokine; rheumatoid arthritis; synovial tissue.
\end{abstract}

Rheumatoid arthritis (RA) is one of the most common articular diseases, characterized by synovitis which leads to the destruction of articular cartilage and bone. Pro-inflammatory cytokines, such as tumor necrosis factor-alpha (TNF- $\alpha$ ) and interleukin (IL)- 6 potentially have pathogenic roles in the establishment of rheumatoid synovitis. ${ }^{1,2}$ Recently, biological therapies targeting TNF- $\alpha$ and IL- 6 have been clinically approved and are now widely used. ${ }^{3}$ However, there are caveats in using the biological preparations, including risk of infection such as tuberculosis, high cost, and variations in efficacy. ${ }^{4}$ Therefore, further investigations are needed to achieve remission of arthritis.
Gap junctions are cell-cell communication channels that consist of multimeric proteins called connexins. They allow the exchange of ions, second messengers, and metabolites between adjacent cells. ${ }^{5}$ Twenty-one human connexin genes have been identified. Among their encoded proteins, connexin $43(\mathrm{Cx} 43)$ is the most widely distributed, and it has been found in synovial cells and tissue. ${ }^{6} \mathrm{C} \times 43$ plays an important role in the regulation of various immune inflammatory processes. $^{7-9}$ In the nervous system, silencing the $\mathrm{Cx} 43$ gene down-regulates the inflammatory response,$^{10}$ while a gap junction blocker (heptanol) inhibits the production of TNF- $\alpha$ in RA synovial tissue. ${ }^{11}$ These reports suggest that the expression 
of $\mathrm{Cx} 43$ in synovial tissue may be involved in RA pathophysiology. Therefore, in this study, we aimed to identify the distribution and expression level of $\mathrm{Cx} 43$ in synovial tissue in patients with $\mathrm{RA}$. We also examined whether small interfering ribonucleic acid (siRNA) targeting $\mathrm{Cx} 43$ could affect the expression of pro-inflammatory cytokines in cultures of human rheumatoid arthritis synovial fibroblasts (RASFs).

\section{PATIENTS AND METHODS}

This study was approved by the hospital ethics committee (the Medical Ethics Committee of Kyoto Prefectural University of Medicine) (RBMR-141-1) during October 2010 and August 2012. Eight patients (2 males, 6 females; mean age $59.5 \pm 2.7$ years; range 52 to 71 years) who fulfilled the American College of Rheumatology (formerly, the American Rheumatism Association) classification criteria for RA were included. ${ }^{12}$ Their clinical characteristics are shown in Table 1. All RA patients were treated with disease-modifying anti-rheumatic drugs; seven patients (RA1, RA2, RA3, RA5, RA6, RA7, and RA8) were treated with methotrexate, one patient (RA2) was treated with bucillamine, and one patient (RA4) was treated with sulfasalazine. Low-dose corticosteroids were used for four patients (RA3, RA4, RA5, and RA7). Two patients (RA1 and RA6) were also treated with a humanized anti-IL-6 receptor (tocilizumab). Patient RA4 had mutilating arthritis, with severe joint destruction. Patients RA2, RA5, RA6, and RA7 showed more erosive disease, with severe destruction in the large joints. Patient RA1 had the least erosive disease. The disease in patient RA8 was well controlled, and severe joint destruction was localized to the small joints of the wrists and feet. Patients RA3 and RA7 had end-stage joint destruction, accompanied by vasculitis; the vasculitis was controlled with $10 \mathrm{mg}$ of corticosteroids per day. Each patient was preoperatively assessed by the Disease Activity Score including a 28 -joint count. ${ }^{13}$

In addition, five patients ( 2 males, 3 females; mean age $68.4 \pm 2.7$ years; range 61 to 81 years) with knee osteoarthritis (OA), diagnosed according to typical clinical features, were included. One female subject (mean age 61 year) with normal knee joint had undergone leg amputation. All OA synovial tissue samples were obtained by total knee arthroplasty.

Clinical research was conducted in compliance with the Declaration of Helsinki. This study was approved by the hospital ethics committee (the Medical Ethics Committee of Kyoto Prefectural University of Medicine) (RBMR-141-1). Written permission was obtained from all subjects who participated in this study.

Table 1. Demographic and clinical features of the study subjects

\begin{tabular}{|c|c|c|c|c|c|c|c|}
\hline Subject/age/gender & $\begin{array}{c}\text { Disease } \\
\text { duration, } \\
\text { years }\end{array}$ & $\begin{array}{c}\text { Larsen } \\
\text { score } \\
\text { for RA }\end{array}$ & $\begin{array}{c}\mathrm{K} / \mathrm{L} \\
\text { score } \\
\text { for OA }\end{array}$ & $\begin{array}{c}\text { CRP level } \\
\text { presurgery, } \\
\text { mg/liter }\end{array}$ & $\begin{array}{l}\text { Source of } \\
\text { synovium }\end{array}$ & DAS $28^{\mathrm{ESR}}$ & Medication \\
\hline \multicolumn{8}{|l|}{ RA patients } \\
\hline RA $1 / 52 / F$ & 8 & IV & - & 0.03 & Knee & 3.89 & TCZ $8 \mathrm{mg} / \mathrm{k} / 4$ week, MTX 6 mg/week \\
\hline RA 2/54/M & 10 & IV & - & 1.21 & Knee & 4.04 & MTX 6 mg/week, BUC 300 mg/day \\
\hline RA 3/64/F & 18 & IV & - & 0.55 & Knee & 3.64 & MTX 8 mg/week, Pred. 10 mg/day \\
\hline RA $4 / 71 / F$ & 29 & IV & - & 0.83 & Elbow & 4.55 & Pred. $10 \mathrm{mg} /$ day, SSZ $2 \mathrm{~g} /$ day \\
\hline RA $5 / 52 / F$ & 24 & IV & - & 2.31 & Knee & 4.66 & MTX 8 mg/week, Pred. 6 mg/day \\
\hline RA $6 / 64 / F$ & 12 & IV & - & 0.04 & Elbow & 5.03 & TCZ $8 \mathrm{mg} / \mathrm{k} / 4$ week, MTX 6 mg/week \\
\hline RA $7 / 52 / F$ & 15 & IV & - & 0.33 & Knee & 3.65 & MTX 6 mg/week, Pred. $10 \mathrm{mg} /$ day \\
\hline RA 8/67/M & 7 & IV & - & 0.29 & Wrist & 4.22 & MTX 8 mg/week \\
\hline \multicolumn{8}{|l|}{ OA patients } \\
\hline OA 9/65/M & - & - & IV & 0.12 & Knee & - & NSAIDs \\
\hline OA $10 / 66 / F$ & - & - & IV & 0.21 & Knee & - & NSAIDs \\
\hline OA $11 / 79 / F$ & - & - & IV & 0.08 & Knee & - & None \\
\hline OA $12 / 68 / \mathrm{F}$ & - & - & IV & 0.09 & Knee & - & None \\
\hline OA $13 / 64 / \mathrm{M}$ & - & - & IV & 0.11 & Knee & - & NSAIDs \\
\hline \multicolumn{8}{|l|}{ Normal subject } \\
\hline $14 / 61 / \mathrm{F}$ & - & - & - & 0.08 & Knee & - & - \\
\hline
\end{tabular}


Synovial tissue was obtained from eight patients with RA (preoperative Disease Activity Score 28 based on erythrocyte sedimentation rate score $4.21 \pm 0.88$ ) and five patients with OA who underwent open synovectomy or total joint replacement, as well as from a patient with normal joint who underwent above-the-knee amputation because of osteosarcoma (Table 1). Three synovial tissue specimens were obtained from random sites during surgery. Each sample was inspected visually to ensure that only inflamed tissue was included. Tissue samples were stored at $-70{ }^{\circ} \mathrm{C}$ until analyzed. For polymerase chain reaction (PCR) analysis, total RNA was isolated from tissue samples that had been homogenized on ice with Isogen reagent (Nippon Gene, Toyama, Japan). For histopathological analysis, tissue samples were fixed in $4 \%$ paraformaldehyde and embedded in paraffin.

Total RNA was extracted using Sepasol-RNA super II (Nacalai Tesque, Kyoto, Japan). Extracted RNAs were reverse transcribed using a PrimeScript ${ }^{\mathrm{TM}}$ RT reagent kit (Takara Bio, Otsu, Japan) according to the manufacturer's directions. Real-time reverse transcriptase polymerase chain reaction(RT-PCR) was performed using a Biosystem 7300 (Applied Biosystems, Foster City, CA, USA) with TaqMan Assay-on Demand gene expression primer/probe sets (Applied Biosystems) for $\mathrm{Cx} 43$ (Assay ID; Hs00748445_s1), TNF- $\alpha$ (Assay ID; Hs01113624_g1), and IL-6 (Hs00985639_m1). All reactions were incubated in a 96-well plate at $95{ }^{\circ} \mathrm{C}$ for 10 minutes, followed by 40 cycles of $95{ }^{\circ} \mathrm{C}$ for 15 seconds, and $60{ }^{\circ} \mathrm{C}$ for one minute. All reactions were performed in triplicate. The let-7a or glyceraldehyde 3-phosphate dehydrogenase gene was used as a control to normalize differences in total RNA levels in each sample. A threshold cycle (Ct) was observed in the exponential phase of amplification, and quantification of relative expression levels was performed using standard curves for target genes and the endogenous control. Geometric means were used to calculate the $\Delta \Delta \mathrm{Ct}$ values and are expressed as $2-\Delta \Delta \mathrm{Ct}$. The value of each control sample was set at 1 and was used to calculate the fold change in target genes.

Paraffin-embedded tissue was sectioned at $5 \mu \mathrm{m}$ and stained with hematoxylin and eosin. For immunohistochemistry, sections were cut to a thickness of $6 \mu \mathrm{m}$ with a cryostat (Bright
Instruments, Huntington, UK) and air dried overnight. The sections were immersed in cold acetone $\left(4{ }^{\circ} \mathrm{C}\right)$ for five minutes, followed by incubation with $0.03 \%$ hydrogen peroxide for 10 minutes to block endogenous peroxidase activities. The tissues were stained with anti-Cx43 antibodies (mouse anti-Cx43 monoclonal antibody, DAKO, Glostlup, Denmark); the antibody was used at a 1:100 dilution in phosphate-buffered saline (PBS) for two hours at $37{ }^{\circ} \mathrm{C}$. The tissues were fixed with 3\% paraformaldehyde and $2 \%$ sucrose in PBS and permeabilized with $0.1 \%$ Triton X-100 in PBS for 10 minutes on ice. Staining was carried out with rhodamine-conjugated rabbit anti-mouse immunoglobulin secondary antibodies (diluted 1:100 in PBS) for 30 minutes at $37^{\circ} \mathrm{C}$.

Fresh synovial tissue was obtained from a separate group of four RA patients. Synovial cells were isolated from the synovial tissue and cultured as previously described. ${ }^{14}$ After the third passage, cells appeared to be morphologically homogeneous fibroblast-like cells. RASFs at passages 4-6 were used for experiments.

Cells were seeded at $2.0 \times 10^{5}$ cells/well in a 6-well plate containing $2 \mathrm{~mL}$ Dulbecco's modified Eagle's medium plus $10 \%$ fetal bovine serum and $1 \%$ penicillin/streptomycin. After cells became adherent, they were treated with recombinant human TNF- $\alpha$ (1 ng/mL) (R\&D Systems, Minneapolis, MN, USA) and then incubated for 24 hours under an atmosphere of $5 \% \mathrm{CO}_{2}$. Cells were washed twice with cold PBS, and then total RNA was isolated with Sepasol-RNA super II reagent. Real-time RT-PCR was performed in triplicate to analyze the expression of $\mathrm{Cx} 43$.

A synthetic siRNA against human Cx43 (siCx43, target sequence: ATGCTTAGAGTGGACTATTAA; Qiagen, Hilden, Germany) and a non-specific-siRNA (siNeg, 1022076 for negative control; Qiagen) were used. Cells were seeded into 6-well plates at a density of $2 \times 10^{5}$ cells/well with $2 \mathrm{~mL}$ of complete Dulbecco's modified Eagle's medium and incubated at $37{ }^{\circ} \mathrm{C}$ in a humidified $5 \% \mathrm{CO}_{2}$ chamber for 12 hours after TNF- $\alpha$ treatment. To evaluate cytokine production, the cells were seeded into 24-well plates at a density of $5 \times 10^{4}$ cells/well. The medium was discarded and replaced with antibiotic-free Dulbecco's modified Eagle's medium supplemented with $10 \%$ fetal 
bovine serum. Twelve hours later, cells were transfected with $80 \mathrm{nM}$ siRNA using RNAiFect (Qiagen) reagent according to the manufacturer's instructions, and then incubated for 12 hours under an atmosphere of $5 \% \mathrm{CO}_{2}$. Cells were washed twice with cold PBS, and then total RNA was isolated with Sepasol-RNA super II reagent. Real-time RT-PCR was performed in triplicate to analyze the expression of Cx43, TNF- $\alpha$, and IL- 6 .

Twenty-four hours after treatment with TNF- $\alpha$, the culture supernatant was harvested, and the concentrations of TNF- $\alpha$ and IL- 6 were measured using ELISA kits for human TNF- $\alpha$ and IL-6 (Gibco BRL, Island, NY, USA). The concentration of these molecules in the supernatant was normalized relative to the total number of cells. The determinations were performed in duplicate for each cell culture preparation.

\section{Statistical analysis}

All data are presented as the mean \pm standard deviation. Statistical analysis was performed among four groups (no treatment; TNF- $\alpha$ (-),
RASFs stimulated with TNF- $\alpha$; TNF- $\alpha(+)$, RASFs stimulated with TNF- $\alpha$ and transfected with siNeg; TNF- $\alpha(+)+$ siNeg, and RASFs stimulated with TNF- $\alpha$ and transfected with siCx43; TNF- $\alpha(+)+\operatorname{siCx} 43)$ in Figure 3 , to compare between TNF- $\alpha(-)$ and TNF- $\alpha(+)$, TNF- $\alpha(-)$ and TNF- $\alpha(+)+$ siNeg, TNF- $\alpha(-)$ and TNF- $\alpha(+)+\operatorname{siCx} 43$, TNF- $\alpha(+)$ and TNF- $\alpha(+)$ + siNeg, TNF- $\alpha(+)$ and TNF- $\alpha(+)+\operatorname{siCx} 43$, TNF- $\alpha(+)+$ siNeg and TNF- $\alpha(+)+\operatorname{siCx} 43$. Analyses were performed using the GraphPad Prism version 6.0 (GraphPad Software, San Diego, CA). At first, homogeneity of variance was tested using the Bartlett's test, and an alpha criterion level of $p<0.01$ was set for all statistical significance. We used one-way analysis of variance test for equality of means among four groups for parametric statics. Then, Tukey-Kramer multiple comparison test was used for post hoc testing. $P$ values less than 0.01 were considered statistically significant.

(a)

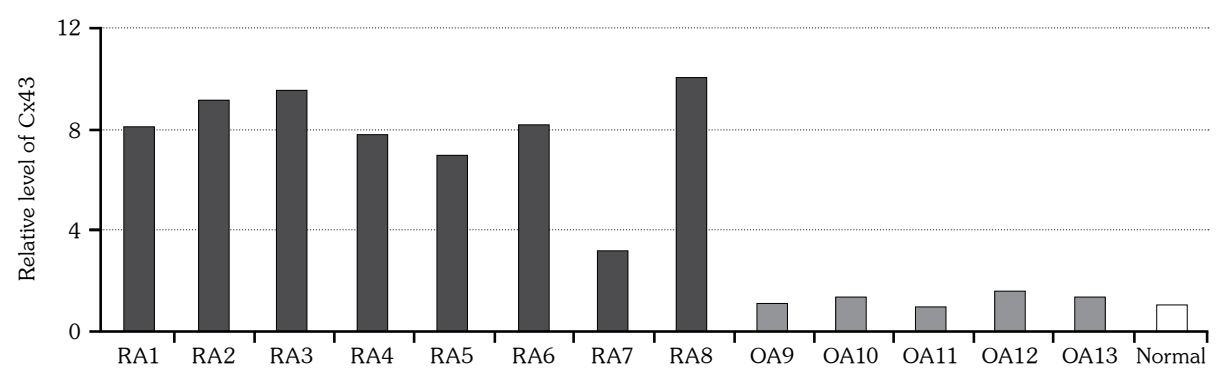

(b)

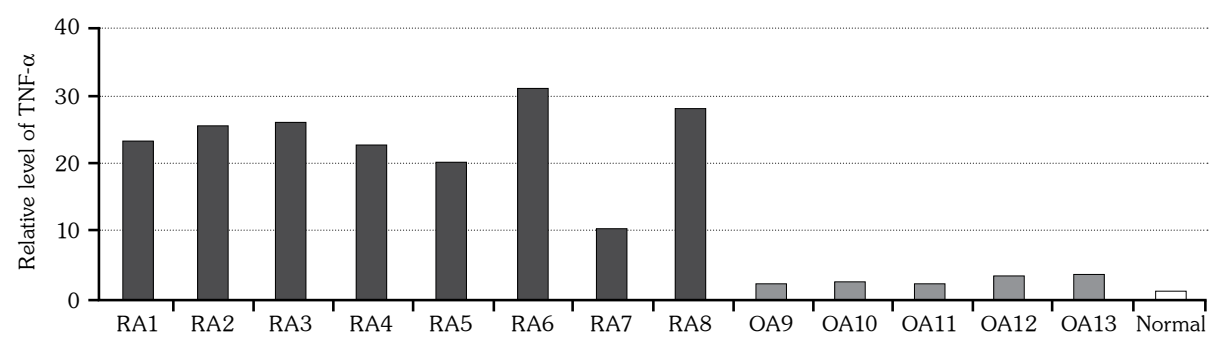

Figure 1. Quantitative reverse transcriptase polymerase chain reaction analysis of the expression of $\mathrm{Cx}_{4} 3$ and TNF- $\alpha$ in synovial tissue from eight patients with RA, five patients with OA, and a normal control subject. GAPDH was used as an internal control for $\mathrm{C} \times 43$ and TNF- $\alpha$. (a) $\mathrm{C} \times 43$ mRNA was strongly expressed in RA synovial tissue. In OA synovia, $\mathrm{Cx} 43$ expression was low. (b) TNF- $\alpha$ mRNA was expressed in the same pattern as that of $\mathrm{Cx} 43$. Normal synovial tissue showed little $\mathrm{Cx} 43$ or TNF- $\alpha$ mRNA expression. Cx43: Connexin 43; TNF- $\alpha$ : Tumor necrosis factor-alpha; RA: Rheumatoid arthritis; OA: Osteoarthritis; GAPDH: Glyceraldehyde 3-phosphate dehydrogenase; mRNA: Messenger ribonucleic acid. 


\section{RESULTS}

In the pathogenesis of RA, TNF- $\alpha$ is an essential mediator of inflammation. To examine a potential link between $\mathrm{Cx} 43$ expression and RA inflammatory activity, mRNA for $\mathrm{Cx} 43$ and TNF- $\alpha$ were analyzed by quantitative RT-PCR in normal synovial tissue and in synovial tissue from RA and OA patients (Figure 1). Cx43 was strongly expressed in RA patients (Figure 1a). TNF- $\alpha$ expression was also up-regulated in synovial tissue from these patients (Figure 1b).

In contrast, in OA synovia, expression of $\mathrm{Cx} 43$ and TNF- $\alpha$ mRNA was low. Expression of $\mathrm{Cx} 43$ or TNF- $\alpha$ was hardly detected in normal synovial tissue. These observations suggest that $\mathrm{Cx} 43$ expression may accompany synovial inflammation caused by TNF- $\alpha$.
To examine the expression of $\mathrm{Cx} 43$ protein in synovial tissue from RA and OA patients, we performed immunohistochemistry. $\mathrm{Cx} 43$ expression was seen in synovial tissue cells in the superficial and sublining layers of all RA patient samples examined (Figure 2), except for patient RA7, in which the expression of $\mathrm{Cx} 43$ and TNF- $\alpha$, as determined by RT-PCR, was low of RA patients (Figure 1). Hematoxylin and eosin staining of synovial tissue from patient RA7 revealed fibrosis and little infiltration of inflammatory cells into synovial tissue. Synovial tissue from the other RA patients showed vigorous proliferation of synovial cells and infiltration of inflammatory cells, typical of the histopathological changes of RA. In synovial tissue from OA patients, hematoxylin and eosin staining revealed little hyperplasia or infiltration
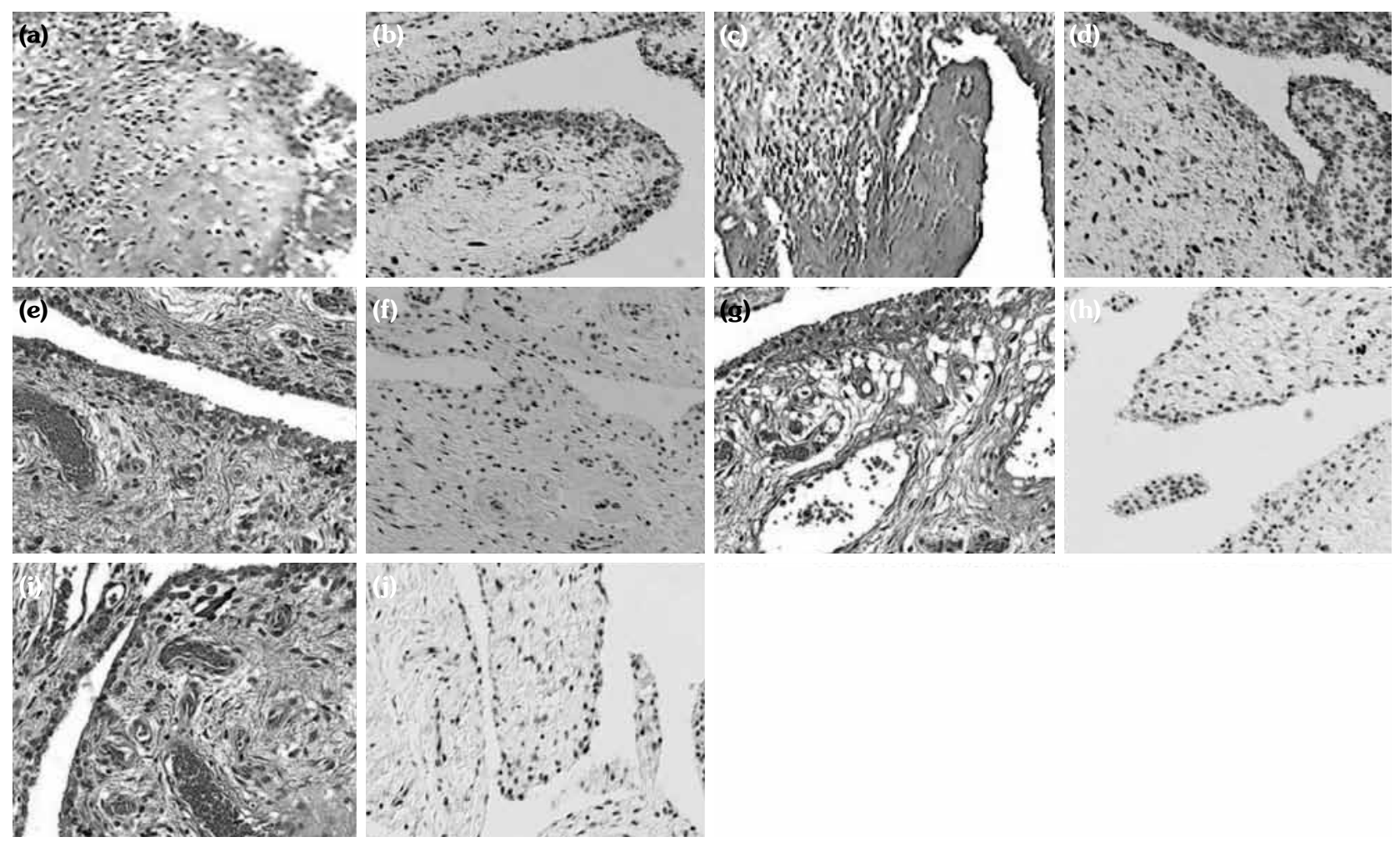

Figure 2. Hematoxylin-eosin staining and immunological staining for $\mathrm{Cx} 43$ in synovial tissue from RA patients RA1 $(\mathbf{a}, \mathbf{b})$, RA3 (c, d), and RA7 $(\mathbf{e}, \mathbf{f})$ and from OA patients OA9 $(\mathbf{g}, \mathbf{h})$ and OA10 (i, j). For each pair of images, H-E staining is shown on the left and immunological staining for $\mathrm{Cx} 43$ on the right. (a-d) Synovial tissue from RA patients RA1 and RA3 showed hyperplasia of the synovial tissue and infiltration of inflammatory cells, as demonstrated by $\mathrm{H}-\mathrm{E}$ staining. Immunological staining for $\mathrm{Cx} 43$ revealed $\mathrm{Cx} 43$ expression in the superficial and sublining layers. $(\mathbf{e}, \mathbf{f})$ Synovial tissue from patient RA7 showed fibrosis, but little infiltration of inflammatory cells, indicating remission of inflammation, as demonstrated by $\mathrm{H}-\mathrm{E}$ staining. Immunological staining for $\mathrm{Cx} 43$ revealed low levels of $\mathrm{Cx} 43$ expression. (g-j) Synovial tissue from OA patients, OA9 and OA10, showed little hyperplasia of the superficial and sublining layers, as demonstrated by H-E staining. (Original magnification x200). H-E: Hematoxylin \& eosin; Cx43: Connexin 43; RA: Rheumatoid arthritis; OA: Osteoarthritis. 
of inflammatory cells in the superficial and sublining layers. In addition, $\mathrm{Cx} 43$ expression was very low in these layers.

We next evaluated the up-regulation of $\mathrm{Cx} 43$ expression in RASFs following stimulation with TNF- $\alpha$ (Figure 3). The level of $\mathrm{Cx} 43$ expression in TNF-siCx43-treated RASFs was reduced to $10.4 \pm 4.8 \%$ compared to that in cells treated with siNeg (data not shown). $\mathrm{Cx} 43$ gene expression, up-regulated by TNF- $\alpha$ stimulation, was significantly inhibited by $\mathrm{siCx} 43$ $(p<0.0001)$ (Figure 3a). Transfection of siCx43 significantly inhibited the TNF- $\alpha$ up-regulation of TNF- $\alpha$ and IL- 6 gene expression $(p<0.001$ and $p<0.001$, respectively) (Figure $3 b$ and $c$ ).
The levels of TNF- $\alpha$ and IL- 6 protein in the TNF- $\alpha(+)+\operatorname{siCx} 43$ group $(71.4 \pm 9.9 \mathrm{pq} / \mathrm{mL}$ and $59.5 \pm 5.3 \mathrm{pq} / \mathrm{mL}$, respectively) were $47.7 \%$ and $48.2 \%$ of the TNF- $\alpha(+)+$ siNeg group $(149.6 \pm 3.2 \mathrm{pq} / \mathrm{mL}$ and $123.5 \pm 24.3 \mathrm{pq} / \mathrm{mL}$, respectively) ( $p=0.008$ and $p=0.009$, respectively) (Figure $3 \mathrm{~d}$ and e). Thus, the up-regulation of proinflammatory cytokines by TNF- $\alpha$ was partially suppressed by transfection of $\mathrm{siCx} 43$ in RASFs.

\section{DISCUSSION}

Connexins, the major proteins of gap junctions, are expressed in various cell types and are (a)

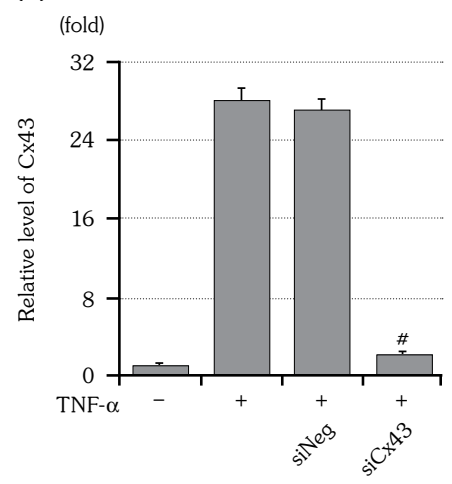

(d)

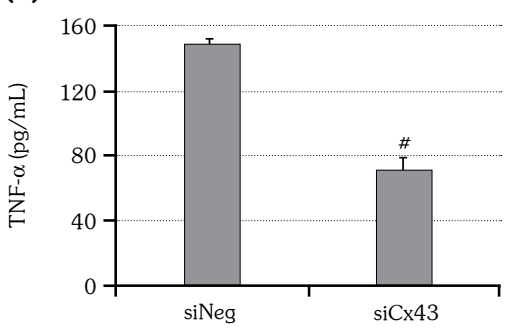

(b)

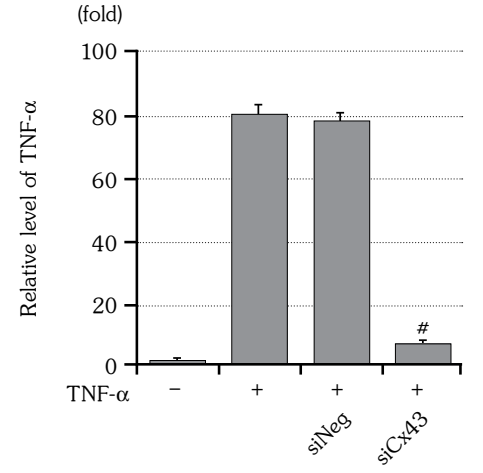

(c)

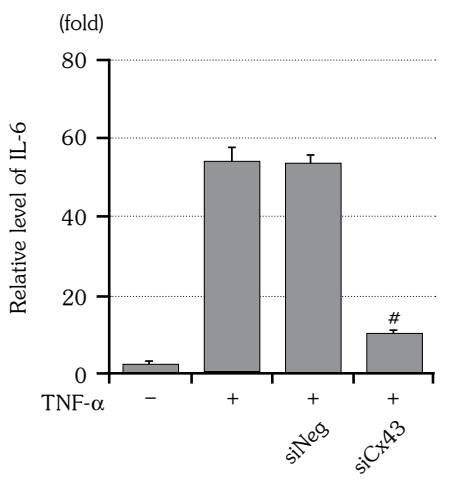

(e)

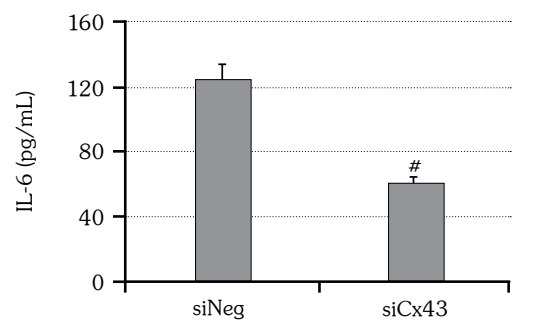

Figure 3. The expression of $\mathrm{Cx} 43$, TNF- $\alpha$ and IL-6 in human RASFs stimulated with recombinant human TNF- $\alpha$ (1 ng/mL) and the effect of siRNA targeting Cx43. (a) siRNA duplexes specific for human Cx43 (siCx43), and non-specific siRNA (siNeg) were transfected into RASFs derived from patients, while control cells were not transfected. After stimulation with TNF- $\alpha$, mRNAs for Cx43 (a), TNF- $\alpha$ (b), and IL-6 (c) genes were evaluated by real-time RT-PCR. After the addition of TNF- $\alpha$, culture supernatants were collected and subjected to ELISA to detect the indicated cytokines $(\mathbf{d}, \boldsymbol{e})$. Cx43 expression was significantly higher in the group of RASFs stimulated with TNF- $\alpha(p<0.001)$ compared to the group of RASFs without stimulation. Cx43 expression was also significantly lower in the group of RASFs transfected with siCx43 $(p<0.001)$ compared to the group of RASFs transfected with siNeg. The high-level of expression of TNF- $\alpha$ and IL- 6 induced by TNF- $\alpha$ was significantly lower in the group of the RASFs transfected with siCx43 $(p<0.001$ and $p<0.001$, respectively) compared to the group of RASFs transfected with siNeg at the mRNA $(\mathbf{b}, \mathbf{c )}$. The high-level of expression of TNF- $\alpha$ and IL-6 induced by TNF- $\alpha$ was also significantly lower in the group of the RASFs transfected with $\operatorname{siCx} 43(\mathrm{p}=0.008$ and $p=0.009$, respectively) at the protein level $(\mathbf{d}, \boldsymbol{e})$. \# $\mathrm{p}<0.01$, versus the siNeg $(\mathrm{n}=4$ in each group). Cx43: Connexin; TNF- $\alpha$ : Tumor necrosis factor-alpha; IL-6: Interleukin-6; RASFs: Rheumatoid arthritis synovial fibroblasts; siRNA: Small interfering ribonucleic acid; RT-PCR: Reverse transcriptase polymerase chain reaction; ELISA: Enzyme-Linked Immunosorbent Assay Test. 
important in the key process of intercellular communication. Connexins 26, 32 and 43 are expressed in synoviocytes, and $\mathrm{Cx} 43$ is the most highly expressed connexin in normal human synovial membranes. ${ }^{15}$ This study showed that Cx43 was highly expressed in RA synovial membranes in comparison with OA or normal synovial membranes, but expression of connexin 26 or 32 was not observed (data not shown). $\mathrm{Cx} 43$ is up-regulated in various tissues and cells by inflammatory stimuli. ${ }^{9,16}$ We have previously revealed that expression of $\mathrm{Cx} 43$ in rat fibroblastlike synoviocytes was increased by stimulation with lipopolysaccharide. We also showed that the expression of $\mathrm{Cx} 43$ was enhanced in synovial tissue from rats with the collagen-induced arthritis (CIA) model of RA. ${ }^{17}$ In this study, we demonstrated that the expression of $\mathrm{Cx} 43$ in RASFs was significantly enhanced by TNF- $\alpha$ stimulation and that high levels of $\mathrm{Cx} 43$ expression was associated with infiltration of inflammatory cells into synovial tissue of RA patients. These findings suggest that increased expression of $\mathrm{Cx} 43$ may be involved in the pathogenesis of RA synovitis.

Pro-inflammatory cytokines, such as TNF- $\alpha$, IL- 6 and IL-1 $\beta$, and metaloproteinase- 3 play dominant roles in the pathobiology of RA. ${ }^{18}$ In our previous study, we demonstrated that siRNA targeting rat Cx43 inhibited TNF- $\alpha$, IL- 6 , and IL-1 $\beta$ induced by lipopolysaccharide in rat fibroblast-like synoviocytes, and that transfection of siRNA targeting rat $\mathrm{Cx} 43$ in the joint significantly reduced synovitis in CIA rats. In a past study, the concentrations of metaloproteinase- 3 in the supernatant of cultured synovia from patients with RA were decreased by adding a gap junction blocker (heptanol). ${ }^{11}$ Additionally, in rabbit, the communication through gap junctions early in IL-1 $\beta$ signal transduction is critical to the process of cytokine-regulated secretion of metalloproteinases by synovial cells. ${ }^{6}$ In this study, we analyzed whether siRNA, which could directly suppress the expression of Cx43, effected the expression of the proinflammatory cytokines. Transfection of siCx43 into RASFs inhibited both gene expression and protein production of the pro-inflammatory cytokines, TNF- $\alpha$ and IL- 6 (mRNA; $p<0.001$ and $p<0.001$, respectively, protein level; $p=0.008$ and $p=0.009$, respectively). These observations suggest that inhibition of $\mathrm{Cx} 43$ may reduce synovitis in patients with RA, via a decrease in the expression of pro-inflammatory cytokines by down-regulation of intercellular communication through gap junctions. However, this hypothesis requires further examination.

In our small cohort of patients, all of the RA patients were being treated with diseasemodifying anti-rheumatic drugs (methotrexate or bucillamine or sulfasalazine), four patients were also receiving corticosteroids and two patients were also receiving an anti-IL-6 monoclonal antibody therapy (tocilizumab). Gupta et al. ${ }^{19}$ reported that increasing $\mathrm{Cx} 43$ expression enhanced the gene expression of IL-6, and knockdown of Cx43 decreased expression of IL- 6 in osteoarthritis synovium. Therefore, we expected that the expression of $\mathrm{Cx} 43$ of synovial tissue was inhibited by tocilizumab which could decrease the expression of IL-6 in synovium. Although, this study showed that the expression of $\mathrm{Cx} 43$ had little difference between the treatment with and without tocilizumab or disease-modifying antirheumatic drugs. Thus, we were unable to evaluate the influence of drug therapy on $\mathrm{Cx} 43$ expression in our study. On the contrary, the expression of both TNF- $\alpha$ and IL- 6 in RASFs was significantly inhibited by the transfection of $\mathrm{siCx} 43$. These suggest that the expression of $\mathrm{Cx} 43$ may be involved in a mechanism of synovitis that is not controlled by the existing therapies targeting pro-inflammatory cytokines and that siCx43 may suppress synovitis of RA patients who have failed biologics therapy such as tocilizumab. Whether or how drug therapy influences $\mathrm{Cx} 43$ expression should be clarified in future studies.

Osteoclasts play an important role in the bone destruction of RA. Cx43 is contained in bone-resorbing osteoclasts, and is involved in regulating the size and multi-nuclearity of human osteoclasts. ${ }^{20,21}$ Several studies have shown that osteoclast fusion is associated with the upregulation of $\mathrm{Cx} 43$ expression in bone marrow cultures, and that a gap-junction inhibitor dramatically inhibited bone resorption, which caused a decrease in the number and activity of osteoclasts. ${ }^{22,23}$ We have also reported that treatment with siRNA targeting rat $\mathrm{Cx} 43$ reduced the number of osteoclastlike cells in areas of pannus invasion into the joints of CIA rats. However, TNF- $\alpha$ plays a key role in the pathogenesis of inflammatory bone resorption and associated morbidity in RA. ${ }^{24}$ 
The present study showed that transfection of siCx43 inhibited the expression of TNF- $\alpha$ in RASFs. These observations suggest that $\mathrm{Cx} 43$ may play a crucial role in osteoclastogenesis of RA through interaction with TNF- $\alpha$ signaling.

In conclusion, the present study demonstrated that $\mathrm{Cx} 43$ was highly expressed in RA synovial tissues, and that suppression of $\mathrm{Cx} 43$ in RASFs inhibited the expression of pro-inflammatory cytokines involved with RA. Cx43 may play an important role in synovitis in RA, and may be a target molecule in new therapies for RA. Further functional analyses to determine the precise role of $\mathrm{Cx} 43$ in the pathogenesis of RA may provide novel diagnostic and/or therapeutic tools.

\section{Declaration of conflicting interests}

The authors declared no conflicts of interest with respect to the authorship and/or publication of this article.

\section{Funding}

This work was supported by MEXT/JSPS KAKENHI, Grant Number 26870493.

\section{REFERENCES}

1. Selmi C, Generali E, Massarotti M, Bianchi G, Sciré CA. New treatments for inflammatory rheumatic disease. Immunol Res 2014;60:277-88.

2. Tak PP, Kalden JR. Advances in rheumatology: new targeted therapeutics. Arthritis Res Ther 2011;13:5.

3. Alivernini S, Laria A, Gremese E, Zoli A, Ferraccioli G. ACR70-disease activity score remission achievement from switches between all the available biological agents in rheumatoid arthritis: a systematic review of the literature. Arthritis Res Ther 2009;11:163.

4. Woolacott N, Bravo Vergel Y, Hawkins N, Kainth A, Khadjesari Z, Misso K, et al. Etanercept and infliximab for the treatment of psoriatic arthritis: a systematic review and economic evaluation. Health Technol Assess 2006;10:1-239.

5. Maeda S, Tsukihara T. Structure of the gap junction channel and its implications for its biological functions. Cell Mol Life Sci 2011;68:1115-29.

6. Kolomytkin OV, Marino AA, Sadasivan KK, Meek WD, Wolf RE, Hall V, et al. Gap junctions in human synovial cells and tissue. J Cell Physiol 2000;184:110-7.

7. Heinrich M, Oberbach A, Schlichting N, Stolzenburg $\mathrm{JU}$, Neuhaus J. Cytokine effects on gap junction communication and connexin expression in human bladder smooth muscle cells and suburothelial myofibroblasts. PLoS One 2011;6:20792.

8. Mori R, Power KT, Wang CM, Martin P, Becker DL. Acute downregulation of connexin 43 at wound sites leads to a reduced inflammatory response, enhanced keratinocyte proliferation and wound fibroblast migration. J Cell Sci 2006;119:5193-203.

9. Li K, Yao J, Shi L, Sawada N, Chi Y, Yan Q, et al. Reciprocal regulation between proinflammatory cytokine-induced inducible NO synthase (iNOS) and connexin43 in bladder smooth muscle cells. J Biol Chem 2011;286:41552-62.

10. Cronin M, Anderson PN, Cook JE, Green CR, Becker DL. Blocking connexin43 expression reduces inflammation and improves functional recovery after spinal cord injury. Mol Cell Neurosci 2008;39:152-60.

11. Nanke $Y$, Kobashigawa T, Yago T, Kawamoto M, Yamanaka $\mathrm{H}$, Kotake $\mathrm{S}$. Tumor necrosis factor- $\alpha$ and matrix metalloproteinase-3 production in rheumatoid arthritis synovial tissue is inhibited by blocking gap junction communication. Exp Immunol 2012;37:237-42.

12. Arnett FC, Edworthy SM, Bloch DA, McShane DJ, Fries JF, Cooper NS, et al. The American Rheumatism Association 1987 revised criteria for the classification of rheumatoid arthritis. Arthritis Rheum 1988;31:315-24.

13. Prevoo ML, van 't Hof MA, Kuper HH, van Leeuwen MA, van de Putte LB, van Riel PL. Modified disease activity scores that include twenty-eight-joint counts. Development and validation in a prospective longitudinal study of patients with rheumatoid arthritis. Arthritis Rheum 1995;38:44-8.

14. Nishida K, Komiyama T, Miyazawa S, Shen ZN, Furumatsu T, Doi H, et al. Histone deacetylase inhibitor suppression of autoantibody-mediated arthritis in mice via regulation of p16INK4a and p21(WAF1/Cip1) expression. Arthritis Rheum 2004;50:3365-76.

15. Marino AA, Kolomytkin OV, Frilot C. Extracellular currents alter gap junction intercellular communication in synovial fibroblasts. Bioelectromagnetics 2003;24:199-205.

16. Balasubramaniyan $\mathrm{V}$, Dhar DK, Warner AE, Vivien Li WY, Amiri AF, Bright B, et al. Importance of Connexin-43 based gap junction in cirrhosis and acuteon-chronic liver failure. J Hepatol 2013;58:1194-200.

17. Tsuchida S, Arai $\mathrm{Y}$, Kishida $\mathrm{T}$, Takahashi KA, Honjo $\mathrm{K}$, Terauchi $\mathrm{R}$, et al. Silencing the expression of connexin 43 decreases inflammation and joint destruction in experimental arthritis. J Orthop Res 2013;31:525-30.

18. Bottini N, Firestein GS. Duality of fibroblast-like synoviocytes in RA: passive responders and imprinted aggressors. Nat Rev Rheumatol 2013;9:24-33.

19. Gupta A, Niger C, Buo AM, Eidelman ER, Chen RJ, Stains JP. Connexin43 enhances the expression of osteoarthritis-associated genes in synovial fibroblasts in culture. BMC Musculoskelet Disord 2014;15:425. 
20. Schilling AF, Filke S, Lange T, Gebauer M, Brink S, Baranowsky A, et al. Gap junctional communication in human osteoclasts in vitro and in vivo. $\mathrm{J}$ Cell Mol Med 2008;12:2497-504.

21. Matemba SF, Lie A, Ransjö M. Regulation of osteoclastogenesis by gap junction communication. $\mathrm{J}$ Cell Biochem 2006;99:528-37.

22. Ransjö M, Sahli J, Lie A. Expression of connexin 43 mRNA in microisolated murine osteoclasts and regulation of bone resorption in vitro by gap junction inhibitors. Biochem Biophys Res Commun 2003;303:1179-85.

23. Ilvesaro J, Väänänen K, Tuukkanen J. Bone-resorbing osteoclasts contain gap-junctional connexin-43. J Bone Miner Res 2000;15:919-26.

24. Zhao B, Grimes SN, Li S, Hu X, Ivashkiv LB. TNFinduced osteoclastogenesis and inflammatory bone resorption are inhibited by transcription factor RBP-J. J Exp Med 2012;209:319-34. 